Bull. Chem. Soc. Ethiop. 2013, 27(3), 347-358.

Printed in Ethiopia

ISSN 1011-3924

DOI: http://dx.doi.org/10.4314/bcse.v27i3.3

(c) 2013 Chemical Society of Ethiopia

\title{
EVALUATION OF THE EFFECT OF VARIOUS DRYING TECHNIQUES ON THE COMPOSITION OF THE PSYCHOACTIVE PHENYLPROPYLAMINO ALKALOIDS OF KHAT (CATHA EDULIS FORSK) CHEWING LEAVES
}

\author{
Minaleshewa Atlabachew ${ }^{1,2}$, Bhagwan Singh Chandravanshi ${ }^{1}$, Mesfin Redi-Abshiro ${ }^{1 *}$, Nelson \\ Torto $^{3}$, Samuel Chigome ${ }^{3}$, and Bellah Oreeditse Pule ${ }^{3}$ \\ ${ }^{1}$ Addis Ababa University, College of Natural Sciences, Department of Chemistry, P.O. Box \\ 1176, Addis Ababa, Ethiopia \\ ${ }^{2}$ Bahir Dar University, College of Science, Program of Chemistry, P.O. Box 79, Bahir Dar, \\ Ethiopia \\ ${ }^{2}$ Rhodes University, Department of Chemistry, Grahamstown, South Africa
}

(Received April 2, 2013; revised July 23, 2013)

\begin{abstract}
The study demonstrated that by freezing or drying under different conditions, cathinone could be detected in the khat (Catha edulis Forsk) samples that have been harvested for more than four months. Freeze drying or freezing in the refrigerator $\left(-20{ }^{\circ} \mathrm{C}\right)$ yielded more than $73 \%$ of cathinone. Air drying, sun drying or oven drying at $60{ }^{\circ} \mathrm{C}$ resulted in a cathinone composition of $57 \%, 42 \%$ and $36 \%$, respectively. The study confirmed that, freshly harvested tender leaves of khat contained exclusively of cathinone but upon sun drying, part of it decomposes to cathine and norephedrine leaving cathinone as a major component. Thus it is wrong to assume that sun drying the leaves can result complete conversion of cathinone to cathine and norephedrine. Furthermore, the results of the study confirmed that it was possible to preserve khat samples for longer periods after freeze drying or deep freezing without significant loss of cathinone.
\end{abstract}

KEY WORDS: Khat, Alkaloids, Cathinone, Cathine, Norephedrine, Storage

\section{INTRODUCTION}

Khat (Catha edulis Forsk) is a flowering large green shrub that grows from eastern to southern Africa, as well as on the Arabian Peninsula [1-5]. The main psychostimulant components of khat are the phenylpropylamino alkaloids: (-)-cathinone [(S)- $\alpha$-aminopropiophenone $],(+)-$ cathine $[(1 S)(2 S)$-norpseudoephedrine], and (-)-norephedrine $[(1 R)(2 S)$-norephedrine] $[2,6]$. Although there are more than 200 identified compounds in khat leaves, the phenylpropylamino alkaloids are primarily considered to be the addictive and reinforcing agents responsible for the continued chewing behavior [2,7].

Since 1980, many papers have reported about the health effects associated with khat. The short term chewing effects have been well discussed $[2,8,9]$ however, not so much information is available regarding the long-term health impact of chewing khat. Few reports from Yemen and elsewhere have indicated that chronic khat consumption may be a leading cause of cancer, cellular toxicity and other metabolic disorders [10-13]. An extensive review by Al-Motarreb et al. [8] and Odenwald [9] about khat chewing and cellular toxicity revealed that some of the literature reports contradicted each other and that the rest were inconclusive as a result of limited data quality and depth. The current understanding of many khat-related topics is still poor and thus further research is urgently needed [14].

Some reports indicated that the conversion of cathinone to cathine occurs in the tender leaves after harvesting, and it is believed to continue rapidly upon drying and during storage. However other reports have argued that room temperature drying alone could not cause appreciable change in the concentration of cathinone [3, 15-18].

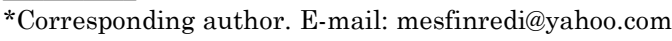


Thus, until recently, it was believed that dried khat plant mainly contained cathine due to the decomposition of cathinone upon drying or storage [16, 17]. As a result almost all pharmacological studies and chemical analysis of khat have been conducted using the fresh leaves of the plant. This has been due to the fact that there was a strong belief that cathinone undergoes significant, if not complete decomposition upon drying and storage.

Currently, cathinone is categorized as Schedule I controlled substance under federal regulations in the United States of America. However, dried leaves have received less attention among the regulatory authorities as it is believed that they contain only cathine that is presumed to be less potent [3]. Even in Australia available evidence suggests that the vast majority of khat import licenses are granted for dried khat implying that the majority of khat being imported is low in the most active constituent cathinone [19].

Recently, Dagne et al. [17] investigated the distribution of cathine and cathinone in different parts of the plant and also studied the variation of the alkaloids upon sun drying of the leaves. They reported that the fresh young leaves of khat mainly contain cathinone but it could not be detected in sun dried young leaves.

Furthermore, using seized khat samples in domestic crime laboratories of USA, Chappell et al. [3] conducted an investigation to identify the stability of cathinone and its kinetic decomposition upon drying and storage. Of the drying conditions considered the authors found higher concentration of cathinone in the ambient-dried sample compared to the heated preparations. However, the authors have claimed that the time between harvesting the samples and analysis was not known and part of the leaves were wilted and showed color change. Thus, it is not possible to conclude the effect of drying on cathinone composition since more than $75 \%$ of cathinone have been decomposed before processing or drying [3].

Lee et al. [16] conducted qualitative study of cathinone composition of khat under different conditions (air drying and freezing at $-2{ }^{\circ} \mathrm{C}$ ). They demonstrated that by air drying the young khat shoots at ambient temperature, cathinone may be detected in khat samples that have been harvested for more than 10 days. Refrigeration for two weeks and freezing for one month of the khat samples also yield identifiable levels of cathinone. However, quantitative data was not reported.

As a result, there is confusion among researchers working on khat related projects about khat preservation without significant loss of the alkaloids. Though it is a general thought that as freezing and freeze drying protocols are the best options to preserve biological samples for long periods of time, their actual effect on the particular samples like khat need to be investigated.

Thus, the objective of this work was to investigate the effect of different sample preservative conditions (air drying, freeze drying, oven drying, sun drying and freezing) so as to recommend a suitable condition for khat sample preservation without imposing a significant change in the alkaloids content.

\section{EXPERIMENTAL}

\section{Materials and reagents}

All the reagents were analytical or HPLC grade. Acetonitrile (Merck KGaA, Darmstadt, Germany), orthophosphoric acid, hydrochloric acid, (Merck Chemicals, Gauteng, South Africa), tripropylamine (Fluka, Switzerland), cathine hydrochloride, (-)-norephedrine, and (+) ephedrine hydrochloride were purchased from Sigma Aldrich. (-)-Cathinone oxalate was isolated from the fresh leaves of the plant. $\mathrm{C}_{18}$ EC QuEChERS bulk sorbent, were obtained from Agilent Technologies (USA). The water used was from MilliQ system from Millipore (Milford, Mass, USA). The mobile phase was filtered through a Whatman membrane filter ( $47 \mathrm{~mm}$ diameter and $2 \mu \mathrm{m}$ pore size) while all the plant extracts were filtered through Acrodisc syringe filter (PVDF membrane with $0.45 \mu \mathrm{m}$ pore size). 
Equipment

The analysis was performed on an Agilent 1200 Series HPLC, Agilent Technologies Inc. (Santa Rosa, CA, USA) equipped with a binary pump and a DAD set at $200 \mathrm{~nm}$. Separation of the compounds was achieved on an Agilent ZORBAX SB-Phenyl column (4.6 x $250 \mathrm{~mm}$, 5 micron). The data was processed by the Agilent ChemStation for LC/MS 2D system software. A reverse-phase method developed by Mathys and Brenneisen [21] was employed to separate and quantitate the alkaloids. The mobile phase consisted of aqueous buffer with $\mathrm{pH} 2.65(8.5 \mathrm{~g} / \mathrm{L}$ orthophosphoric acid and $0.3 \mathrm{~mL} / \mathrm{L}$ tripropylamine) and $5 \%$ acetonitrile in water at a flow of 1.5 $\mathrm{mL} / \mathrm{min}$ in a gradient mode. ${ }^{1} \mathrm{H}$ and ${ }^{13} \mathrm{C}$ NMR spectroscopy (Bruker Avance $400 \mathrm{NMR}$ spectrometer at $400 \mathrm{MHz}$, Germany) was used to confirm the identity of isolated oxalate salts.

\section{Plant material collection}

Sample collection for cathinone and cathine isolation in the form of oxalate salt. Samples were collected from Sebeta (which is about $25 \mathrm{~km}$ from Addis Ababa), Ethiopia and transported within two hours to the Chemistry Department of Addis Ababa University, Ethiopia in an ice box. As soon as the samples were brought to the laboratory, twigs and tender leaves were taken from part of the sample and immediately extracted as mentioned below. The remaining portion of the sample was taken and dried under sun light. The dried sample was ground and extracted on a hot plate. Confirmation of the isolates was done in the Chemistry Department, Addis Ababa University using ${ }^{1} \mathrm{H}$ and ${ }^{13} \mathrm{C}$ NMR spectroscopy. Further confirmation was also done by HPLC-DAD at Rhodes University, South Africa.

Sample collection for investigation of effect of sample preservation. Samples were collected from the Bahir Dar area, Ethiopia more specifically from Zenzelima (which is about $550 \mathrm{~km}$ from Addis Ababa) and transported to the Chemistry Department of Addis Ababa University, Ethiopia over night in the ice box. As soon as it arrived in the laboratory, the edible parts of the plant (the upper and lower sections of the leaves) were taken and portion of the samples were kept in a deep freeze $\left(-20{ }^{\circ} \mathrm{C}\right)$ while the rest were subjected to drying under different conditions (air drying, freeze drying, oven drying at $60{ }^{\circ} \mathrm{C}$ and sun drying) until a constant weight was obtained. The dried and ground samples were packed in to polyethylene bag and kept in moisture free and light protected environment. The refrigerated samples in ice box and the dried samples were taken to Rhodes University, South Africa for chemical analysis.

\section{Isolation of cathinone and cathine}

The procedure reported by Dagne et al. [17] was used to isolate the salt of cathinone from the fresh leaves of the plant. Namely, $500 \mathrm{~g}$ of the sample was crushed under liquid nitrogen and subsequently extracted in $0.1 \mathrm{M} \mathrm{HCl}$ for $2 \mathrm{~h}$ by placing on a magnetic stirrer. The extract was filtered by using suction filtration and the filtrate was subjected to liquid-liquid extraction (x3) using diethyl ether $\left(\mathrm{Et}_{2} \mathrm{O}\right)$ and $(\mathrm{x} 1)$ using benzene to remove pigments and other fat soluble metabolites. The acidic aqueous solution was alkalinized to $\mathrm{pH} 10$ with $10 \% \mathrm{NaOH}$ and extracted with $\mathrm{Et}_{2} \mathrm{O}(\mathrm{x} 2)$. Oxalic acid $\left(1 \%\right.$ in $\left.\mathrm{Et}_{2} \mathrm{O}\right)$ was added drop wise to the $\mathrm{Et}_{2} \mathrm{O}$ extract and the extract left to stand for $20 \mathrm{~h}$ in the refrigerator $\left(4{ }^{\circ} \mathrm{C}\right)$ to yield cathinone oxalate $(150 \mathrm{mg})$ as white precipitate.

As suggested by Dagne et al. [17], an attempt was made to isolate cathine oxalate following the above procedure except dried and powdered samples were used in place of the fresh leaves. 
Quantifying khat alkaloids in samples processed under different conditions

Khat alkaloids were extracted from all the dried samples using matrix solid phase dispersion (MSPD) [22] while the alkaloids were extracted from the refrigerated sample using the method reported by $[21]$.

\section{Extraction of khat alkaloids from dried samples}

For the extraction of the alkaloids from the dried samples, previously developed method by our group was used [22]. Briefly, a $0.25 \mathrm{~g}$ aliquot of the sample (sun dried, oven dried, freeze dried or air dried) was placed in a mortar and mixed with $0.75 \mathrm{~g}$ of $\mathrm{C}_{18}$ QuEChERS bulk sorbent and $100 \mu \mathrm{L}$ of (+)-ephedrine hydrochloride (IS) $(500 \mu \mathrm{g})$ [22]. The mixture was then homogenized in the agate mortar using an agate pestle to obtain a homogenous mixture. The blend was then transferred into a $10 \mathrm{~mL}$ syringe with a paper frit at the bottom. The sample was covered with another paper frit and the flow of the solution through the syringe was driven by the pressure of vacuum manifold pump or can be compressed manually using the syringe plunger. The alkaloids were eluted directly with $10 \mathrm{~mL}$ of $0.1 \mathrm{M} \mathrm{HCl}$ and the residue after evaporation of the extract to dryness was dissolved in the mobile phase. Eluents were filtered through a PVDF membrane and injected into the HPLC system. Two replicates were performed for each sample assay and two replicate HPLC-DAD analyses were performed on each filtrate.

\section{Extraction of khat alkaloids from fresh samples}

For the extraction of fresh samples, a method proposed by Mathys and Brenneisen [21] was used. Briefly, $1.04 \mathrm{~g}$ of fresh khat sample was mixed with $100 \mu \mathrm{L}$ of $5 \mu \mathrm{g} / \mu \mathrm{L}$ of ephedrine hydrochloride (IS) and crushed in the mortar with pestle. The powdered sample was then extracted 3 times with a total of $50 \mathrm{~mL} 0.1 \mathrm{M} \mathrm{HCl}$ in ultrasonic bath for $45 \mathrm{~min}$. The combined filtrate was evaporated to dryness at $40{ }^{\circ} \mathrm{C}$ using vacuum rotary evaporator. The residue was dissolved in the mobile phase (acetonitrile-water 5:95, containing $8.5 \mathrm{~g} / \mathrm{L}$ orthophosphoric acid $(85 \%)$ and $0.3 \mathrm{~mL} / \mathrm{L}$ tri-propylamine) and passed through a pre-conditioned $\mathrm{C}_{18} \mathrm{SPE}$ cartridge with $3 \mathrm{~mL}$ methanol and $3 \mathrm{~mL}$ of (acetonitrile-water 5:95, containing $8.5 \mathrm{~g} / \mathrm{L}$ orthophosphoric acid $(85 \%)$ and $0.3 \mathrm{~mL} / \mathrm{L}$ tri-propylamine). Then the cartridge was eluted with a portion of $1 \mathrm{~mL}$ followed by $3 \mathrm{~mL}$ of acetonitrile-water 5:95, containing $8.5 \mathrm{~g} / \mathrm{L}$ orthophosphoric acid $(85 \%)$ and $0.3 \mathrm{~mL} / \mathrm{L}$ tri-propylamine. Duplicate analysis was carried out.

\section{RESULT AND DISCUSSION}

\section{Isolation of khat alkaloids}

Preliminary investigation was made by taking all the edible portion of the leaves (the upper and lower but the softest part of the leaves). However, identifiable amount of cathine were detected in it (result not shown). Then only twigs and tender leaves (near the tip of the shoot) were taken for the analysis. Pure cathinone oxalate was isolated and characterized by ${ }^{1} \mathrm{H}$ NMR and ${ }^{13} \mathrm{C}$ NMR (Figures 1-3). The multiplicity and chemical shifts in the ${ }^{1} \mathrm{H}$ NMR, ${ }^{13} \mathrm{C}$ NMR spectra as well as orientation of the DEPT spectra confirmed to what was expected theoretically and to the reported data by Dagne et al. [17]. Tables 1 and 2 show the interpretation of the ${ }^{1} \mathrm{H}$ NMR and ${ }^{13} \mathrm{C}$ NMR data. Results of the analysis showed that tender leaves (near the tip of the plant) contain only cathinone but not the other alkaloids (cathine and norephedrine). This result 
corroborates the earlier report of Dagne et al. [17]. However, the lower sections but edible portion of the leaves may contain cathine in addition to the major alkaloids (cathinone).

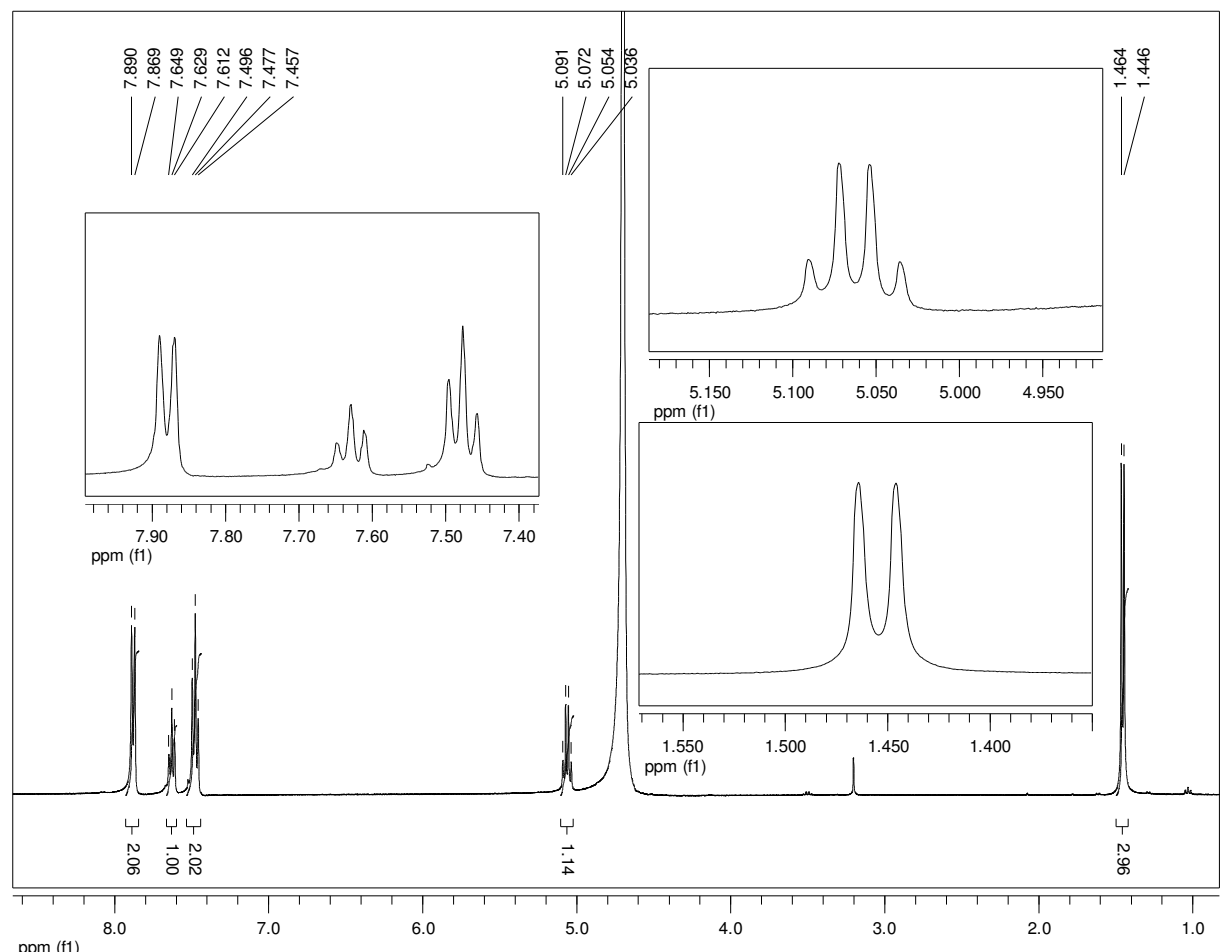

Figure 1. ${ }^{1} \mathrm{H}$ NMR spectrum of cathinone oxalate run in $\mathrm{D}_{2} \mathrm{O}$.

Table 1. Interpretation of ${ }^{1} \mathrm{H}$ NMR data for cathinone.

\begin{tabular}{|c|c|c|c|}
\hline Chemical shift (ppm) & Multiplicity & Assignment & Literature chemical shift [17] \\
\hline 7.88 & Doublet & $2 \mathrm{H}$ & 7.89 \\
\hline 7.63 & Triplet & $1 \mathrm{H}$ & 7.67 \\
\hline 7.47 & Triplet & $2 \mathrm{H}$ & 7.48 \\
\hline 5.00 & Quartet & $1 \mathrm{H}$ & 5.06 \\
\hline 1.46 & Doublet & $3 \mathrm{H}$ & 1.46 \\
\hline
\end{tabular}




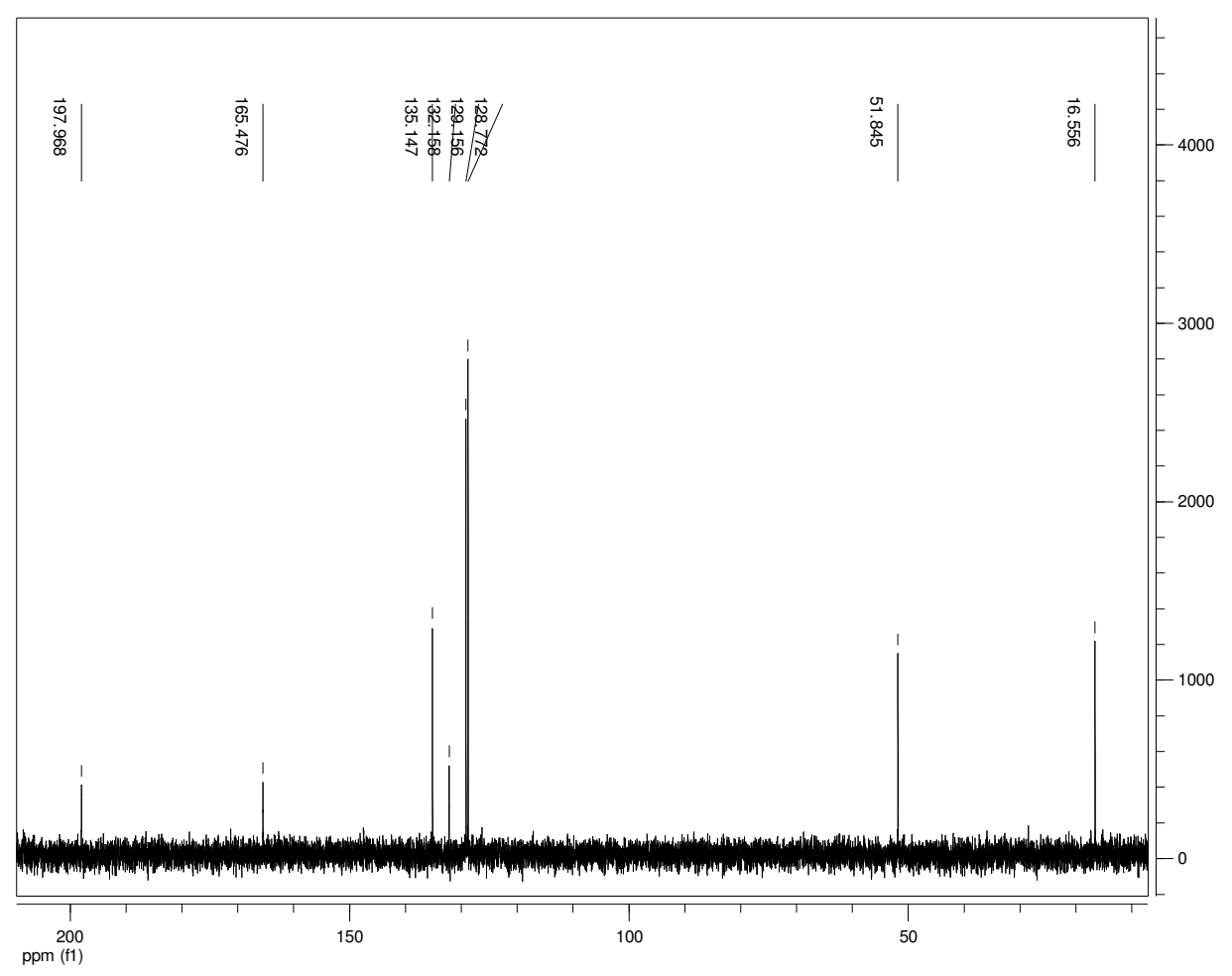

Figure 2. ${ }^{13} \mathrm{C}$ NMR spectrum of cathinone oxalate.

Table 2. Interpretation of ${ }^{13} \mathrm{C}$ NMR data for cathinone.

\begin{tabular}{|c|c|c|c|}
\hline Chemical shift (ppm) & Multiplicity & Assignment & Literature chemical shift [17] \\
\hline 197.9 & Singlet & C-1 & 198.1 \\
\hline 135.1 & Singlet & C-4' & 135.2 \\
\hline 132.2 & Singlet & C-1' & 132.3 \\
\hline 129.2 & Singlet & C-2', ${ }^{\prime}$ & 129.3 \\
\hline 128.8 & Singlet & C-3',5' & 128.9 \\
\hline 51.8 & Singlet & C-2 & 51.9 \\
\hline 16.6 & Singlet & C-3 & 16.6 \\
\hline
\end{tabular}

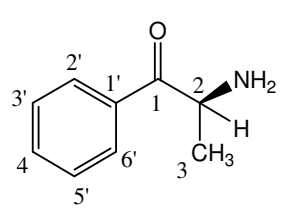

S-(-)-Cathinone

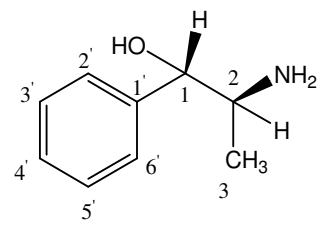

(+)-Cathine

Bull. Chem. Soc. Ethiop. 2013, 27(3) 


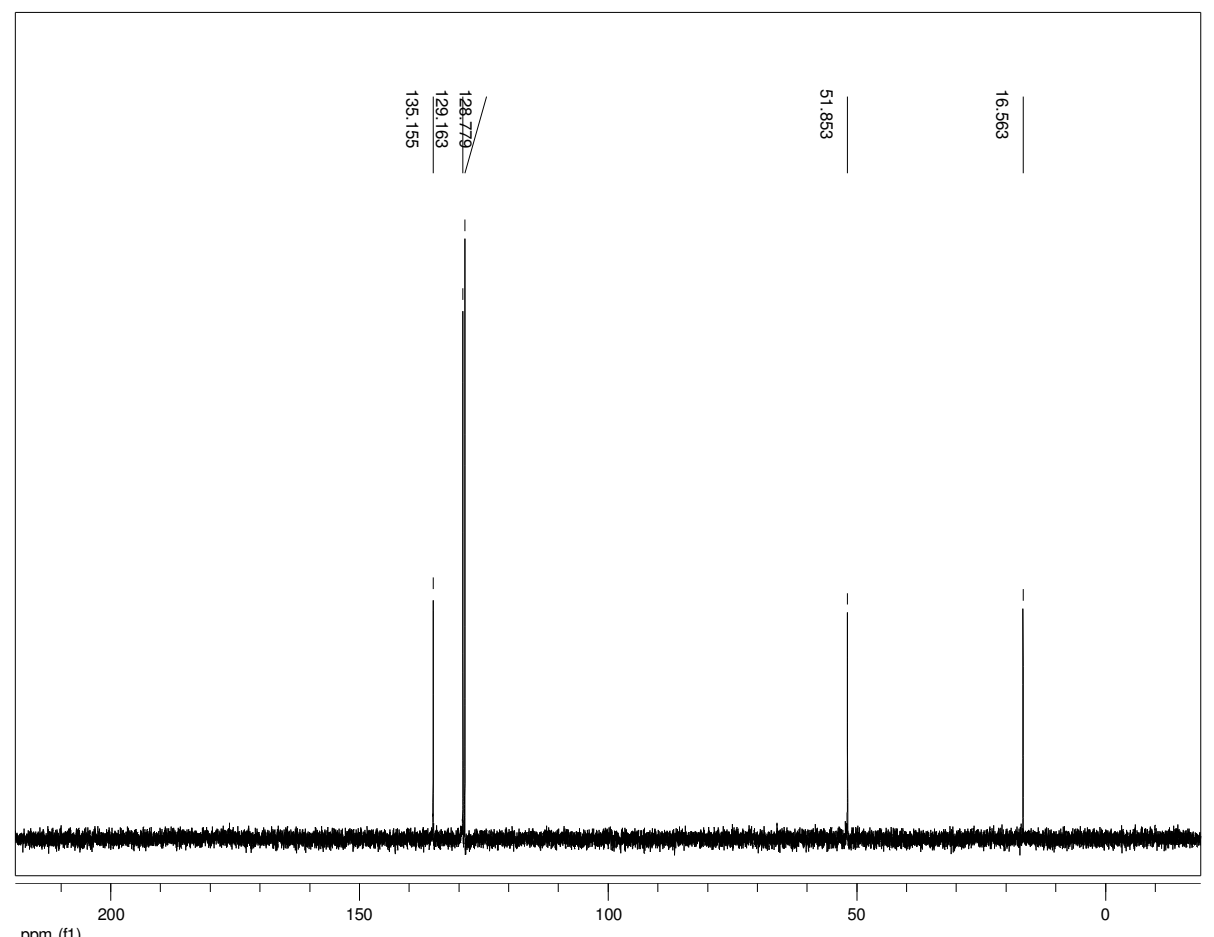
ppm (11)

Figure 3. DEPT ${ }^{13} \mathrm{C}$ NMR spectrum of cathinone oxalate.

Figures 4 and 5 show the ${ }^{1} \mathrm{H}$ NMR and ${ }^{13} \mathrm{C}$ NMR spectra, respectively, for the isolated compounds as oxalate salt from the sun dried khat sample. Looking at the figures, ${ }^{1} \mathrm{H}$ NMR signal at $\delta 7.23(\mathrm{~m}, 5 \mathrm{H}), 4.46(\mathrm{~d}, 1 \mathrm{H}), 3.4(\mathrm{~m}, 1 \mathrm{H})$ and $0.96(\mathrm{~d}, 3 \mathrm{H})$ and ${ }^{13} \mathrm{C}$ NMR $\left(\mathrm{D}_{2} \mathrm{O}\right): \delta 74.7$ (C-1), 51.8 (C-2), 14.5 (C-3), 128.9 (C-1'), 128.8 (C-2, 6'), 126.7(C-3', 5') and 128.7 (C-4') corresponds to protons of cathine/norephedrine (Dagne et al. [17]). While from ${ }^{1} \mathrm{H}$ NMR, the signal at $\delta=7.83,7.58,7.42,5$ and 1.46 belongs to protons of cathinone (in the above table). Similarly, from ${ }^{13} \mathrm{C}$ NMR, the signal $\delta(198.1)$ is a characteristic peak for carbonyl carbon of cathinone. Therefore, cathinone was identified as a major component in a sun dried sample. Thus it is wrong to assume that sun drying of khat samples completely decompose cathinone to cathine and norephedrine as stated elsewhere [17].

The HPLC-DAD chromatogram of the isolated cathinone oxalate from the fresh leaves and the mixtures of alkaloids obtained from the dried leaves of khat collected from Sebeta are shown in Figure 6.

\section{Quantification of khat alkaloids in differently processed khat samples}

In this study, five preservative methods have been compared and results of the analysis are shown in Table 3. For each sample types duplicate analysis and two HPLC runs were recorded. Mean and standard deviation of the four runs $(n=4)$ were tabulated for each sample types.

Looking at the table, all the preservative methods were found to retard the complete conversion of cathinone. Refrigeration and freeze drying protocols were markedly retarded the 
conversion of cathinone to cathine and norephedrine. However, oven drying and sun drying protocols were susceptible to cathinone degradation to the corresponding alcohols.

As shown in Figure 6A the fresh leaves is mainly composed of cathinone, i.e. cathine and norephedrine are negligible. Therefore, the concentration of cathonone in the fresh leaves was assumed to be $>99 \%$.

Comparing the preservation protocols with each other, the percentage of cathinone after deep freezing, freeze drying, room temperature drying, sun drying and oven drying was $77 \%$, $73 \%, 57 \%, 42 \%$ and $36 \%$, respectively.

The proportion of cathinone among the alkaloids was highest in the deep frozen sample (77\%) and freeze dried sample (73\%) compared to the air dried and heated preparations (sun drying and oven drying). This data corroborates previous reports as drying under ambient temperature or higher temperature as well as sun drying reduces cathinone [3, 15-18]. However, it has been confirmed that sun drying or drying at about $60{ }^{\circ} \mathrm{C}$ and stored for more than four months could not completely degrade the cathinone to cathine and norephedrine unlike previous reports [17].

A similar trend was observed with the proportion of cathine and norephedrine, where lower concentrations were noticed in the freeze dried and deep frozen samples compared with oven dried and sun dried counter parts. This observation further confirmed the assertion that a cathinone decomposes to cathine and norephedrine upon drying $[3,16]$.

Even though air drying protocol could result in a lower concentration of cathinone $(57 \%)$ compared with freeze drying and deep freezing, it is far better way to preserve cathinone compared with sun drying and oven drying.

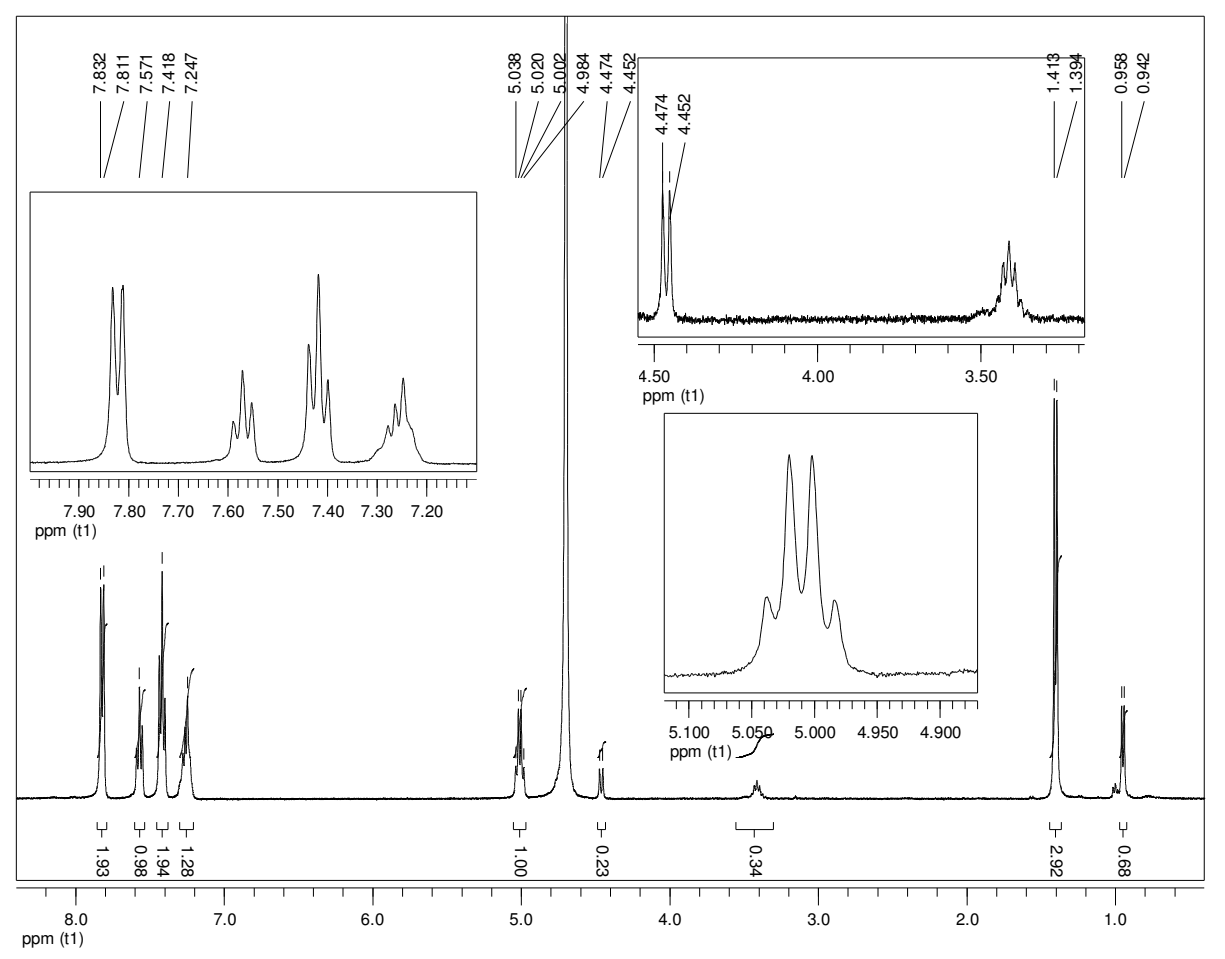

Figure 4. ${ }^{1} \mathrm{H}$ NMR spectrum of isolate of sun dried khat sample as oxalate salt run in $\mathrm{D}_{2} \mathrm{O}$. 


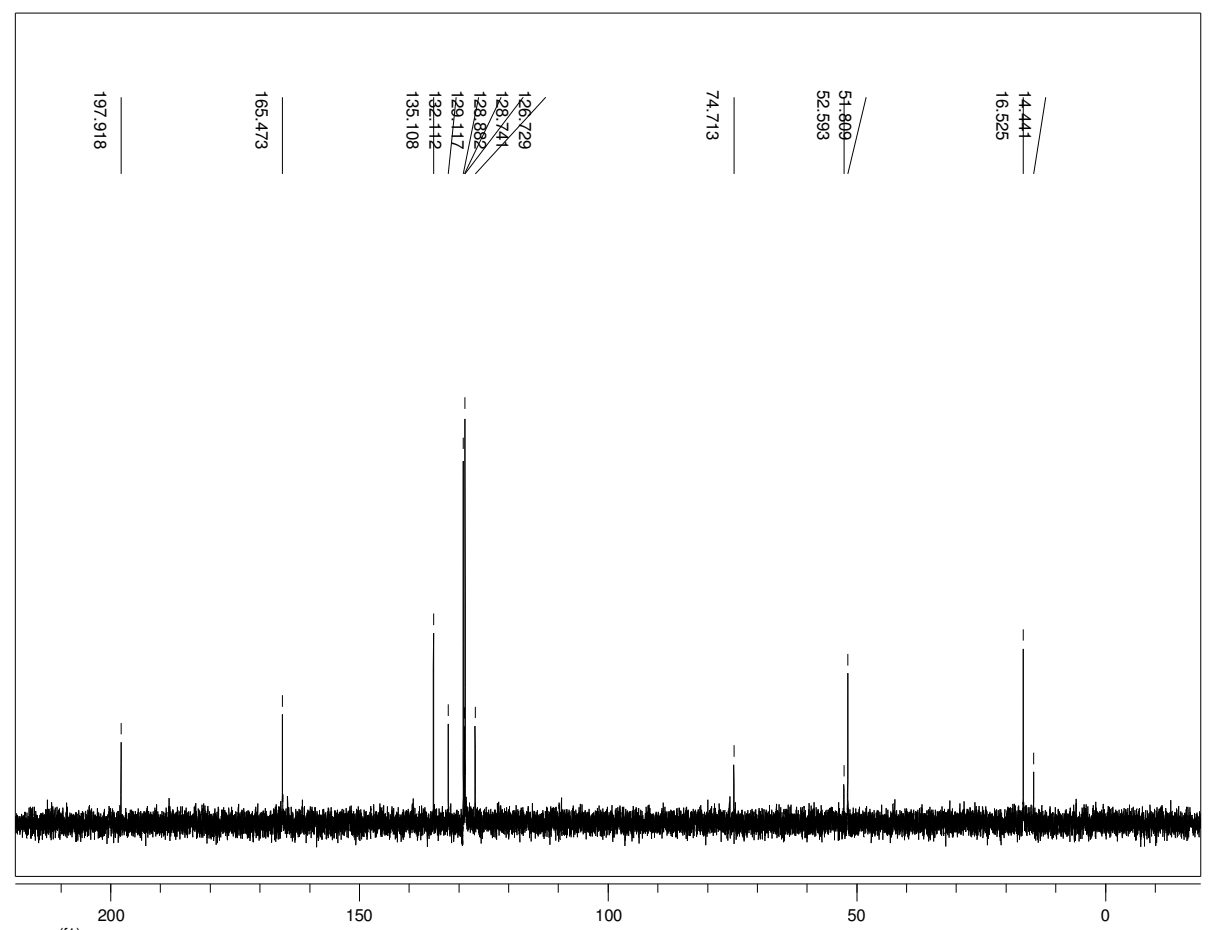

ppm (f1)

Figure $5 .{ }^{13} \mathrm{C}$ NMR spectrum of isolate of sun dried khat sample as oxalate salt

Chappell et al. [3] examined the effect of air drying, oven drying and microwave oven drying conditions and then compared their results with the un-dried sample. They found the percentage of cathinone (11-16\%) and $13 \%$ in the dried and un-dried samples respectively, which is far lower than the present study. This might be due to the fact that the sample considered by them was originally started wilting before treated with the specified conditions, where by majority of the cathinone undergone reduction to cathine and norephedrine. And hence their data could not lead us to precisely conclude about effect of drying on cathinone preservation.

Furthermore, the ratio of norephedrine to cathine was poorly correlated under different drying conditions. Thus, there might be other additional decomposition products of cathinone under different drying conditions. 


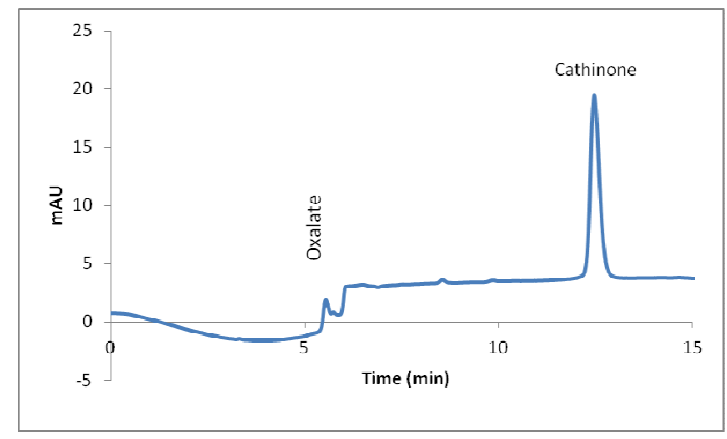

(A) $5 \mu \mathrm{L}$ injection of $25 \mu \mathrm{g} / \mathrm{mL}$ solution

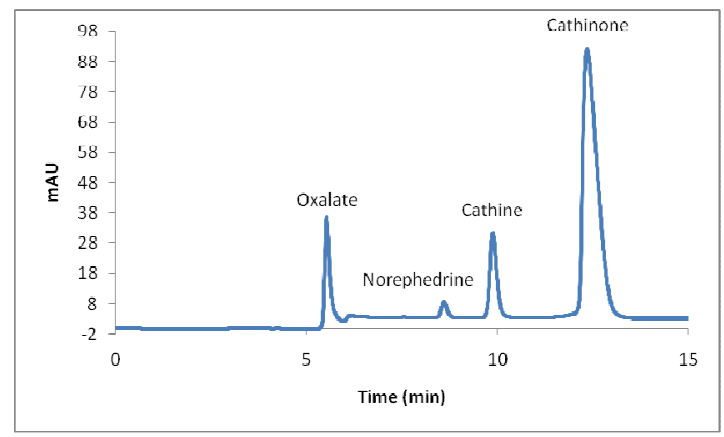

(B) $5 \mu \mathrm{L}$ injection of $300 \mu \mathrm{g} / \mathrm{mL}$ solution

Figure 6. Chromatograms of isolate of fresh leaves (A) and sun dried leaves (B) as oxalate salt.

Table 3. Psychoactive phenylpropylamino alkaloids composition of khat and its dried preparations.

\begin{tabular}{|l|c|c|c|c|}
\hline \multirow{2}{*}{ Preparation conditions } & \multicolumn{4}{|c|}{ Mean alkaloids concentration $\left(\mathrm{x} \pm \mathrm{SD}^{\mathrm{a}}\right)$ in $\mu \mathrm{g} / \mathrm{g}$ on dry weight basis } \\
\cline { 2 - 5 } & \multicolumn{4}{|c|}{ Percentage sum of the alkaloids } \\
\cline { 2 - 5 } & Norephedrine & Cathine & Cathinone & Sum \\
\hline Room-temp. dried & $778 \pm 17$ & $2208 \pm 244$ & $3913 \pm 255$ & 6899 \\
& $11 \%$ & $32 \%$ & $57 \%$ & $100 \%$ \\
\hline Freeze dried & $59 \pm 59$ & $1266 \pm 49$ & $4701 \pm 243$ & 6562 \\
& $9 \%$ & $19 \%$ & $73 \%$ & $100 \%$ \\
\hline Sun dried & $1279 \pm 88$ & $2641 \pm 71$ & $2763 \pm 184$ & 6683 \\
& $19 \%$ & $39 \%$ & $42 \%$ & $100 \%$ \\
\hline Oven dry & $1375 \pm 73$ & $2604 \pm 59$ & $2196 \pm 50$ & 6175 \\
& $22 \%$ & $42 \%$ & $36 \%$ & $100 \%$ \\
\hline Deep freezed & $628 \pm 82$ & $975 \pm 69$ & $5426 \pm 412$ & 7028 \\
& $9 \%$ & $14 \%$ & $77 \%$ & $100 \%$ \\
\hline Freeze dried (kerti type khat) & $208 \pm 20$ & $2235 \pm 44$ & $3392 \pm 182$ & 5835 \\
& $4 \%$ & $38 \%$ & $42 \%$ & $100 \%$ \\
\hline
\end{tabular}

${ }^{\mathrm{a}} \mathrm{SD}=$ standard deviation of $\mathrm{n}=4$ runs. ${ }^{\mathrm{b}}$ The conversion factor for frozen sample was 3.52 (3.52 $\mathrm{g}$ of frozen sample yielded $1 \mathrm{~g}$ of dry sample).

Bull. Chem. Soc. Ethiop. 2013, 27(3) 
Evaluation of the analytical method

The analytical method used in this study was evaluated by studying the recovery and reproducibility of the spiked duplicate samples and duplicate HPLC analysis $(n=4)$. All the compounds were extracted efficaciously and displayed good recoveries (89-92\%) with \%RSD values ranged from 2.6 to $7.2 \%$ for $n=4$ runs [22]. The limit of detection (LOD) of the method was also calculated using the calibration curve parameters after a linear calibration curves were produced by plotting the analyte/IS peak area ratios against the corresponding concentrations of the khat amines. A good linearity response greater than 0.999 was obtained for the three analyte for the concentration range of $0.76-230 \mu \mathrm{g} / \mathrm{mL}, 1.00-125 \mu \mathrm{g} / \mathrm{mL}$ and $1.00-250 \mu \mathrm{g} / \mathrm{mL}$ of cathinone, cathine and norephedrine, respectively. The slope and intercept value for calibration curve was $y=0.023 x-0.009\left(R^{2}=0.9998\right)$ for cathinone, $y=0.013 x-0.006\left(R^{2}=0.9995\right)$ for cathine and $y=0.014 x-0.01\left(R^{2}=0.9996\right)$ for norephedrine. The LOD was established using $\mathrm{LOD}=3.3 \mathrm{x}(\mathrm{s} / \mathrm{S})$, where $\mathrm{s}$ is the standard deviation of the intercept and $\mathrm{S}$ is the slope of the curve. The LOD obtained for cathinone, cathine and norephedrine were 1.29, 1.72 and 1.72 $\mu \mathrm{g} / \mathrm{mL}$, respectively [22].

\section{CONCLUSION}

This study provides conclusive results about khat alkaloids composition variation when different sample pretreatment techniques are considered and khat samples are stored for about four months. The study demonstrates that by freezing or drying under different conditions, cathinone could be detected in the khat samples. Storing the samples in the refrigerator after freeze drying or deep freezing can preserve more than $73 \%$ of cathinone unlike other pretreatment techniques like air drying, sun drying and oven drying at about $60{ }^{\circ} \mathrm{C}$ temperature and hence it is wrong to assume that sun drying the leaves can result complete decomposition of cathinone. The results confirmed that it is possible to preserve khat samples for longer period after freeze drying or deep freezing without significant loss of cathinone. Isolation of pure salt of cathinone from freshly picked twigs and shoot near the tips of khat plant proved the assertion that these parts of the plant consist exclusively of cathinone while cathine and norephedrine are produced in the plant during maturation, drying or during storage and extraction.

\section{ACKNOWLEDGMENTS}

The authors would like to thank Rhodes University, South Africa and Addis Ababa University, Ethiopia for providing laboratory facilities. Prof. Ermias Dagne is duly acknowledged for his kind cooperation to use the NMR facilities. Mr. Minaleshewa Atlabachew is indebted to Addis Ababa University and Bahir Dar University, Ethiopia for their financial support.

\section{REFERENCES}

1. Balint, E.E.; Falkay, G.; Gabor, A.; Balint, G.A. Wien. Klin. Wochenschr. 2009, 121, 604.

2. Feyissa, A.M.; Kelly, J.P. Progr. Neuro-Psychopharmacol. Biol. Psych. 2008, 32, 1147.

3. Chappell, J.S.; Lee, M.M. Forensic Sci. Int. 2010, 195, 108.

4. Laussmann, T.; Meier-Giebing, S. Forensic Sci. Int. 2010, 195, 160.

5. Gambaro, V.; Arnoldi, S.; Colombo, M.L.; Dell'Acqua, L.; Guerrini, K.; Roda, G. Forensic Sci. Int. 2012, $217,87$.

6. Krizevski, R.; Dudai, N.; Bar, E.; Lewinsohn, E. J. Ethnopharmacol. 2007, 114, 432.

7. Geisshusler, S.; Brenneisen, R. J. Ethnopharmacol. 1987, 19, 269. 
8. Al-Motarreb, A.; Al-Habori, M.; Broadley, K.J. J. Ethnopharmacol. 2010, 132, 540.

9. Odenwald, M. Sucht. 2007, 53, 9.

10. Al-Akwa, A.A.; Shaher, M.; Al-Akwa, S.; Aleryani, S.L. J. Ethnopharmacol. 2009, 125, 471.

11. Kassie, F.; Darroudi, F.; Kundi, M.; Schulte-Hermann, R.; Knasmuller, S. Int. J. Cancer 2001, 92, 329.

12. Al-Hebshi, N.N.; Nielsen, O.; Skaug, N. Acta Odont. Scand. 2005, 63, 136.

13. Al-Ahdal, M.N.; Mcgarry, T.J.; Hannan, M.A. Mut. Res. 1988, 204, 317.

14. Editorial. J. Ethnopharmacol. 2010, 132, 537.

15. Szendrei, K. Bull. Narc. 1980, 32, 5.

16. Lee, M.M. J. Forensic. Sci. 1995, 40, 116.

17. Dagne, E.; Adugna, Y.; Kebede, E.; Atilaw, Y. Ethiop. e-J. Res. Innov. Foresight, 2010, 2 , 7.

18. Brenneisen, R.; Geisshusler, S. Pharm. Acta Helv. 1985, 60, 290.

19. Fitzgerald, J. Khat: a literature review. Louise Lawrence Pty Ltd. Available at http://www.ceh.org.au/downloads/Khat_report_FINAL.pdf, accessed in 2012.

20. Dawson, B.A.; Black, D.B.; Lavoie, A.; LeBelle, M.J. J. Forensic Sci. 1994, 39, 1026.

21. Mathys, K.; Brenneisen, R. Pharm. Acta Helv. 1993, 68,121.

22. Atlabachew, A.; Torto, N.; Chandravanshi, B.S.; Redi, M. Chromatographia 2013, 76, 401.

23. Krizevski, R.; Dudai, N.; Bar, E.; Dessow, I.; Ravid, U.; Lewinsohn, E. Israel J. Plant Sci. 2008, 56, 207.

24. Kalix, P.; Braenden, O. Pharmacol. Rev. 1985, 37, 149. 